УДК 548.5:549.613.4

\title{
МУЛЛИТ И ЕГО ИЗОМОРФНЫЕ ЗАМЕЩЕНИЯ ОБ3ОР
}

\author{
(C) 2018 Е. Г. Яроцкая, П. П. Федоров
}

\author{
Институт общей физики им. А. М. Прохорова РАН, ул. Вавилова, 38, 119991 Москва, Россия \\ e-mail: yar461@yandex.ru
}

Поступила в редакцию 18.09.2018

\begin{abstract}
Аннотация. Рассмотрена фазовая диаграмма системы $\mathrm{SiO}_{2}-\mathrm{Al}_{2} \mathrm{O}_{3}$. Представлен обзор методов синтеза муллита, в т. ч., обжигом природных алюмосиликатов, из расплава методом Чохральского, методом Вернейля из геля, и твердофазным методом из шихты стехиометрического состава. По литературным данным установлено, что параметры ромбической решетки и габитус кристаллов муллита напрямую зависят от величины соотношения алюминия и кремния в исходной шихте, содержания примесей, способа термической обработки и формы введения в шихту исходных компонентов. На размер кристаллов муллита влияет наличие фторида алюминия в шихте, что при определенных соотношениях позволяет получать конечный продукт в виде вискерсов. Рассмотрено воздействие минерализаторов на выход муллита: фториды щелочных металлов его уменьшают, а сульфаты и хлориды увеличивают, а также влияют на вязкость и структуру расплава. С этой целью рассмотрены различные добавки и их влияние на характер синтеза, структуру и свойства. Выявлены структурные особенности кристаллической решетки муллита, влияющие на изоморфные замещения. Рассмотрена возможность получения изоморфно замещенных разновидностей муллитов. В работе приведены оптические характеристики изоморфно замещенных муллитов, содержащих $d$-элементы.
\end{abstract}

Ключевые слова: муллит, синтез, структура, габитус, вискерсы, изоморфные замещения.

DOI: https://doi.org/10.17308/kcmf.2018.20/626

\section{ВВЕДЕНИЕ}

Муллит - аналог очень редкого природного минерала, состоящего из оксидов алюминия и кремния, важнейший технический материал [1-41]. Это единственный алюмосиликат, устойчивый при высоких температурах, и одна из основных кристаллических фаз во многих керамических материалах, которая имеет, как правило, призматическую или изометрическую морфологию.

Муллит входит в состав высокоглиноземистых огнеупоров, фарфора, шамота и др. Монолитная керамика из муллита отличается химической устойчивостью к кислотам, щелочам и окислительным средам, обладает высокой стойкостью к износу и термоударам. Она применяется, в том числе, как субстрат для катализаторов и кремниевых солнечных батарей, в качестве подложки в электронике, компонента зубных протезов, как антибактериальный материал.

Наибольшую практическую ценность представляют нитевидные и игольчатые кристаллы мул- лита [38-40]. Благодаря высоким армирующим свойствам этих кристаллов муллит используется в различных композиционных материалах на основе стекол, фарфора, керамики, полимеров [1316]. Введение нитевидного муллита в стекломассу в количестве $0.1-1$ \% стимулирует кристаллообразование, и такая стеклокерамика обладает более высокими механическими и термическими свойствами, чем исходное стекло. Армирование иглами муллита корундовой керамики повышает ее стойкость к термоудару в 50-100 раз. Муллит применяется в качестве наполнителя при производстве электроизоляционных масс для высоковольтных высокочастотных кабелей. Муллит нашел применение при создании фторопластов и резин повышенной прочности и износостойкости. В последние годы привлекают внимание композиты из муллита и металлических сплавов [26, 27].

В то же время проблемы фазообразования в системе $\mathrm{Al}_{2} \mathrm{O}_{3}-\mathrm{SiO}_{2}$, способы получения порошков муллита заданной гранулометрии и формы частиц, 
формирование керамики и композиционных материалов, возможность легирования муллита ставят важные фундаментальные вопросы в таких областях науки, как описание несоразмерных фаз в многомерной кристаллографии, теории фазовых переходов и понятия фазы, механизмах роста и образования кристаллов, а также теории изо- и гетеровалентного изоморфизма.

\section{КРИСТАЛЛИЧЕСКАЯ СТРУКТУРА И ФАЗОВАЯ ДИАГРАММА}

Основой всех структур силикатов является четверная координация кремния по отношению к кислороду. Атом кремния (ионный радиус $\mathrm{Si}^{4+} 0.39 \AA$ ) и окружающие его четыре атома кислорода образуют прочно связанную группу $\mathrm{SiO}_{4}$ в виде тетраэдра, вершины которого приходятся на центры атомов кислорода, а атом кремния расположен в центре тетраэдра. Из-за близости размеров ионных радиусов алюминий (ионный радиус $\mathrm{Al}^{3+} 0.57 \AA$ ) также может, наряду с октаэдрической, принимать и тетраэдрическую координацию с образованием тетраэдра $\mathrm{AlO}_{4}$. В ромбической структуре силлиманита $\mathrm{Al}_{2} \mathrm{SiO}_{5}$ присутствуют колонки из октаэдров $\mathrm{AlO}_{6}$, соединенных ребрами. Эти колонки связаны между собой двойными лентами, состоящими из чередующихся тетраэдров со связанными вершинами $\mathrm{SiO}_{4}$ и $\mathrm{AlO}_{4}$ [42]. Кристаллическая структура муллита сходна со структурой силлиманита, но отличается от нее более или менее случайным распределением $\mathrm{Al}$ и $\mathrm{Si}$ в тетраэдрах и смещением атомов кислорода вокруг катионов. В структуре присутствует чередование тетраэдров. При этом имеет место гетеровалентное изоморфное замещение по уравнению:

$$
2 \mathrm{Si}^{4+}+\mathrm{O}^{2-}=2 \mathrm{Al}^{3+}+\mathrm{V}_{\mathrm{O}}
$$

c образованием кислородных вакансий и формированием фазы переменного состава с общей формулой $\mathrm{Al}_{2}\left(\mathrm{Al}_{2 x} \mathrm{Si}_{2-2 x}\right) \mathrm{O}_{10-x}$. Муллит можно рассматривать как фазу алюмосиликата, элементарная ячейка которого не содержит целого числа атомов кислорода со статистическими распределенными вакансиями. Стремление к упорядочению вызывает серию (т. н. «дьявольская лестница») фазовых переходов порядок-беспорядок с формированием, несоразмерных фаз $[8,10]$. Наиболее устойчивыми и энергетически выгодными являются составы $2 \mathrm{Al}_{2} \mathrm{O}_{3} \cdot \mathrm{SiO}_{2}$ и $3 \mathrm{Al}_{2} \mathrm{O}_{3} \cdot 2 \mathrm{SiO}_{2}$.

Параметры ромбической решетки муллита зависят от разных факторов: величины отношения $\mathrm{Al} / \mathrm{Si}$, содержания примесей, способа термической обработки. Габитус кристаллов муллита - удлиненно-призматический и игольчатый. Главные формы (001), (010), (100) и (110).

Фазовая диаграмма системы $\mathrm{Al}_{2} \mathrm{O}_{3}-\mathrm{SiO}_{2}$ изучалась многократно $[17,34]$, см. рис. 1. Фаза муллита имеет ширину около 3 мол. \%, причем равновесный состав ее смещается при понижении температуры в область меньших содержаний алюминия. Температурная область термодинамической устойчивости фазы муллита $1890-932{ }^{\circ} \mathrm{C}$. Силлиманит при $1200{ }^{\circ} \mathrm{C}$ разлагается на высокотемпературный муллит и $\mathrm{SiO}_{2}$. Характер плавления муллита был предметом многочисленных дискуссий. Можно констатировать, что при нормальном давлении он

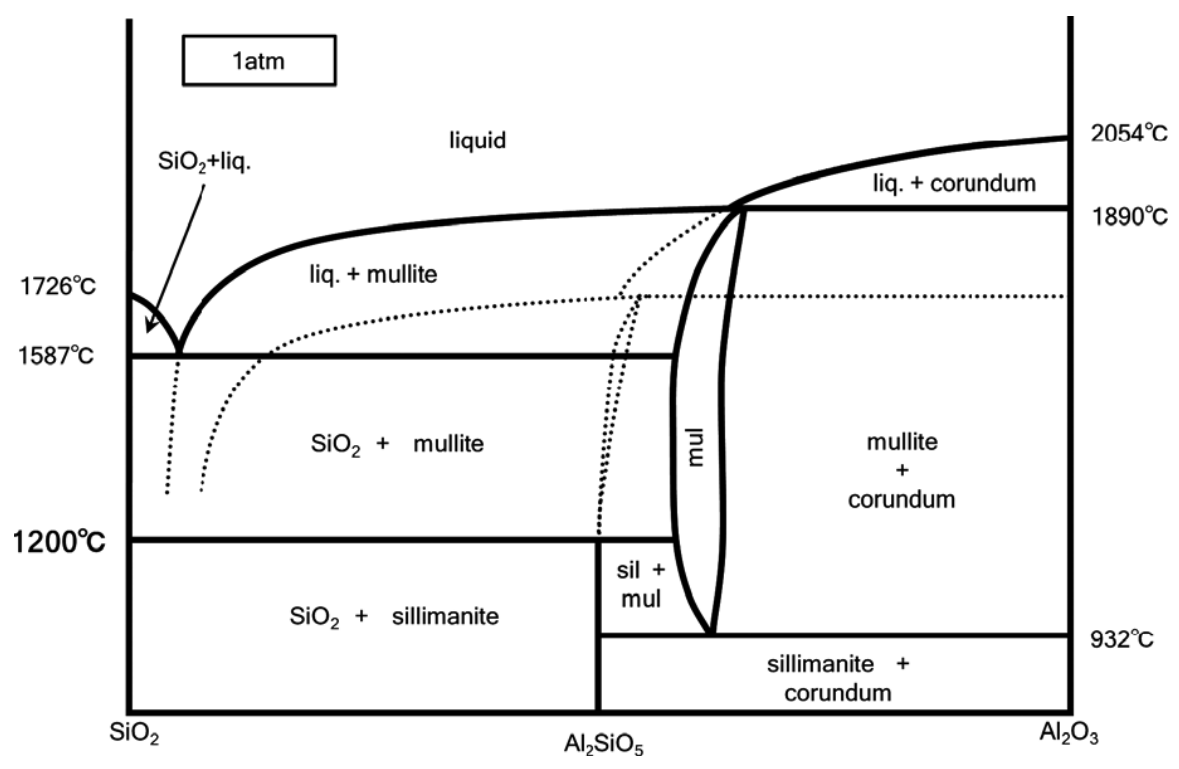

Рис. 1. Фазовая диаграмма системы $\mathrm{SiO}_{2}-\mathrm{Al}_{2} \mathrm{O}_{3}$ [34]

[Fig. 1. Phase diagram $\mathrm{Al}_{2} \mathrm{O}_{3}-\mathrm{SiO}_{2}$ system [34]] 
является промежуточным между конгруэнтным и инконгруэнтным и соответствует окрестности точки бифуркации фазовой диаграммы [43]. Практическая устойчивость муллитовой фазы далеко выходит за границы термодинамической устойчивости. Ее можно рассматривать как бертоллид - твердый раствор кремнезема в неустойчивой модификации t- $\mathrm{Al}_{2} \mathrm{O}_{3}$, стабилизированной гетеровалентными изоморфными замещениями $[44,8]$.

Необходимо отметить, что распад муллита чрезвычайно заторможен, и эта фаза практически вполне устойчива при температурах ниже эвтектоидного равновесия $\left(932^{\circ} \mathrm{C}\right.$, см. рис. 1$)$.

\section{СПОСОБЫ ПОЛУЧЕНИЯ}

Существует несколько способов получения муллита.

Монокристаллы муллита длиной 2-2.5 см с диаметром около 1 см выращены Бауэром В. и др. методом Вернейля. В качестве шихты использовалась смесь чистого геля кремнезема и алюминиевых квасцов.

Из расплава методом Чохральского Guse W. и Mateika D. вырастили монокристаллы муллита оптического качества диаметром до 2 см и длиной до 5 см состава $2 \mathrm{Al}_{2} \mathrm{O}_{3} \cdot \mathrm{SiO}_{2}$ в иридиевом тигле в атмосфере чистого азота. Скорость вытягивания составляла $1.5 \mathrm{Mм/ч} \mathrm{при} \mathrm{скорости} \mathrm{вращения} 10 \mathrm{мин}^{-1}$. Кристаллы росли вдоль оси [001].

Нитевидные и игольчатые кристаллы муллита, преимущественно состава $3 \mathrm{Al}_{2} \mathrm{O}_{3} \cdot 2 \mathrm{SiO}_{2}$, получают при обжиге природных алюмосиликатов и твердофазном синтезе из оксидов. В промышленном масштабе кристаллы муллита короткопризматического габитуса получают высокотемпературным $\left(1800{ }^{\circ} \mathrm{C}\right)$ обжигом каолинита. При прокаливании каолинита образуется первичный муллит, при охлаждении после обжига из расплава кристаллизуется вторичный муллит в виде игл.

В Японии организовано производство синтетического муллитового порошка, осуществляемого обжигом смеси каолиновой глины с оксидом алюминия. Увлажненное сырье смешивают, обрабатывают на шаровой мельнице, затем обезвоживают на фильтр-прессе и вакуумном ленточном прессе. Выходящий брус разрезают на брикеты, сушат и обжигают во вращающейся печи при температуре $1800^{\circ} \mathrm{C}$. При термообработке происходит образование клинкера с кристаллами муллита размером 50-60 мкм. Конечный продукт содержит от 87 до 99 \% муллита.

Примером твердофазного образования муллита является муллитизация фарфора. В фарфоре разли- чают первичный муллит, образующийся при обжиге глинистых минералов, и вторичный, кристаллизующийся при более высокой температуре из алюмосиликатного расплава.

Образование муллита при нагревании шихты стехиометрического состава зависит от продолжительности обжига, а также от формы введения в шихту исходных компонентов.

Значительное влияние на вязкость и структуру расплава, а также, соответственно, и на характеристики конечного продукта оказывают минерализаторы [6]. Влияние минерализаторов на процесс муллитообразования подробно изучен П. П. Будниковым, М. Ф. Назаренко, А. Шортером, Х. Окудой, К. Муром, Р. Хауссоном, В. Де Кейзером и другими исследователями. Влияние минерализаторов на степень муллитизации в стехиометрических составах увеличивается в ряду: $\mathrm{TiO}_{2}-\mathrm{NaCl}-\mathrm{CaCO}_{3}-\mathrm{MnO}_{2}-$ $\mathrm{LiCl}-\mathrm{MgCO}_{3}-\mathrm{LiF}$. Добавка LiF при $1400{ }^{\circ} \mathrm{C}$ приводит к синтезу 100 \% муллита. Значительно ускоряют процесс муллитообразования добавки катионов II группы периодической системы химических элементов, введение Тi, В и Мn существенного влияния не оказывают, а добавки $\mathrm{Fe}^{3+}$ и $\mathrm{Ni}^{3+}$ замедляют синтез. Габитус кристаллов муллита зависит от введенного в шихту минерализатора: при добавке $\mathrm{BeO}$ образуются игольчатые кристаллы, введение $\mathrm{B}_{2} \mathrm{O}_{3}$ приводит к появлению волокнистых агрегатов, а добавка 5 \% СаО вызывает образование изометрических кристаллов муллита.

Размеры синтезируемых кристаллов муллита зависят от температуры обжига шихты и количества фторида в ней. При температуре обжига до $1100{ }^{\circ} \mathrm{C}$ образуются нитевидные кристаллы муллита. При повышении температуры габитус кристаллов становится игольчатым. Увеличение содержания фторида алюминия в шихте позволяет получать более удлиненные кристаллы муллита в виде сферолитов.

Андреев В. А. [11] отмечает, что минерализаторы существенно облегчают ход процесса кристаллизационно-псевдокоагуляционного структурообразования, добавки сдвигают начало возникновения расплава за счет образования эвтектик в область низких температур; добавки $\mathrm{CaO}, \mathrm{MgO}$, $\mathrm{ZnO}, \mathrm{BaO}$ значительно увеличивают скорость муллитообразования.

Действие минерализаторов зависит также от типа вводимого соединения. Так, фториды щелочных металлов уменьшают выход муллита, сульфаты и хлориды - увеличивают. Добавки фторида и карбоната лития снижают температуру кристалли- 


\section{Е. Г. ЯРОЦКАЯ, П. П. ФЕДОРОВ}

зации муллита до $550{ }^{\circ} \mathrm{C}$. Введение фторида алюминия в количестве $10 \%$ масс. способствует образованию муллита при $650{ }^{\circ} \mathrm{C}$.

Роль минерализаторов выполняют также примеси, содержащиеся в природных сырьевых материалах.

\section{ИЗОМОРФНЫЕ ЗАМЕЩЕНИЯ В МУЛЛИТЕ}

Изоморфные замещения в муллите разнообразны [5]. Факторами, определяющими возможность изоморфных замещений различных атомов, является наличие в кристаллической решетке двух типов координационных полиэдров - октаэдров и тетраэдров, а также наличие пустот размером до 0.067 нм [4]. Эти особенности структуры муллита позволяет без ее нарушения внедрять различные изоморфные ионы с различными размерами ионного радиуса. Повышение температуры, в общем, увеличивает степень вхождения посторонних ионов в решетку муллита.

Важно отметить: поскольку муллит является фазой переменного состава, в нем реализуется «внутренний изоморфизм» кремния и алюминия в соответствии с уравнением (1). Характерно, что эти замещения реализуются только в кислородных тетраэдрах.

Широкие области твердых растворов образуются при замещении $\mathrm{Al}$ и $\mathrm{Si}$ на их аналоги по Периодической системе - B, Ga, Ge. Бор замещает кремний, причем входит в структуру как в виде треугольников $\mathrm{BO}_{3}$, так и тетраэдров $\mathrm{BO}_{4}$. В системе $\mathrm{AlF}_{3}-$ $\mathrm{SiO}_{2}-\mathrm{B}_{2} \mathrm{O}_{3}$ был получен борат алюминия состава $9 \mathrm{Al}_{2} \mathrm{O}_{3} \cdot 2 \mathrm{~B}_{2} \mathrm{O}_{3}$ в виде игольчатых кристаллов - длиннопризматических вискерсов диаметром 0.5-10 мкм и длиной 5-100 мкм [45]. В системах муллит $-\mathrm{Ga}_{2} \mathrm{O}_{3}$ и германиевый муллит $-\mathrm{Ga}_{2} \mathrm{O}_{3}$ были получены галлиевый и германиевый муллит с предельной концентрацией твердых растворов (мол. доля $\mathrm{Ga}_{2} \mathrm{O}_{3}$ до 35 и $25 \%$ соответственно). Для галлия и германия характерны координационные числа как 4, так и 6.

Довольно высокой растворимостью в муллите характеризуются катионы переходных металлов, таких как $\mathrm{Ti}^{4+} \mathrm{V}^{3+}, \mathrm{Cr}^{3+}, \mathrm{Fe}^{3+}$. В основном эти катионы замещают алюминий в октаэдрических позициях. По данным [1] в структуру синтетического муллита может входить до $2-4 \% \mathrm{TiO}_{2}$, до 8-10\% $\mathrm{Cr}_{2} \mathrm{O}_{3}$. Согласно [7], при $1400{ }^{\circ} \mathrm{C}$ в решетку муллита внедряется не более $1 \% \mathrm{TiO}_{2}, 3-4 \% \mathrm{Cr}_{2} \mathrm{O}_{3}$. По современным данным максимальная растворимость $\mathrm{V}_{2} \mathrm{O}_{3}, \mathrm{Cr}_{2} \mathrm{O}_{3}, \mathrm{Fe}_{2} \mathrm{O}_{3}, \mathrm{Ga}_{2} \mathrm{O}_{3}$ в муллите составляет $6 \pm 0.5$ мол. \% [5].
Согласно [6], внедрение $\mathrm{Ca}^{2+}$ и $\mathrm{Mg}^{2+}$ приводит к разрушению решетки муллита с образованием корунда, анортита и сапфирина. Однако, согласно [7], происходит внедрение в решетку муллита катионов $\mathrm{Ca}^{2+}, \mathrm{Be}^{2+}, \mathrm{Mg}^{2+}$ в процессе обжига при $1400{ }^{\circ} \mathrm{C}$. С увеличением температуры у $\mathrm{Ca}^{2+}$ способность к внедрению снижается, а у $\mathrm{Be}^{2+}$ и $\mathrm{Mg}^{2+}$ увеличивается.

Изучение фазовой равновесной системы $\mathrm{Cu}_{2} \mathrm{O}$ $\mathrm{SiO}_{2}-\mathrm{Al}_{2} \mathrm{O}_{3}$ привело к разработке технологии изготовления медного алюмосиликатного стекла [20].

Включение в состав муллита крупных редкоземельных элементов возможно только для малых концентраций [5]. $\mathrm{La}_{2} \mathrm{O}_{3}$, синтезированный зольгель методом, вводился в муллит стехиометрического состава $3 \mathrm{Al}_{2} \mathrm{O}_{3}: 2 \mathrm{SiO}_{2}$. Исследования образцов показали, что добавление оксида лантана повышает образование стекловидной фазы состава $\mathrm{Al}_{2} \mathrm{O}_{3}-\mathrm{La}_{2} \mathrm{O}_{3}-\mathrm{SiO}_{2}$ и увеличивает плотность, почти достигая значений теоретической плотности муллита [26].

Муллит-никелевые нанокомпозитные волокна с наночастицами Ni регулируемого размера, полученные золь-гель методом, проявили свойства ферромагнетизма [29].

Учитывая практический интерес синтезируемых материалов для фотоники и противоречия в литературных данных, авторы данной работы исследовали [3] вхождение в муллит изоморфных примесных катионов $d$-элементов: $\mathrm{C}^{3+}, \mathrm{V}^{3+}, \mathrm{Ni}^{3+}$, $\mathrm{Co}^{3+}, \mathrm{Fe}^{3+}, \mathrm{Mn}^{3+}$. Количество изоморфной примеси варьировалось от 0.2 до 3 на 1 формульную единицу. Изучались продукты синтеза, полученные из исходной шихты, в которой изменялось отношение $\left(\mathrm{Al}_{2} \mathrm{O}_{3}-x\right) / \mathrm{A} 1 \mathrm{~F}_{3}$ от 0 до 2.5, где $x$ - содержание изоморфно замещаемого компонента. Полученные результаты позволяют классифицировать взаимодействие муллита с вводимыми в состав оксидами следующим образом:

1) оксиды, катионы которых образуют твердые растворы на основе муллита: $\mathrm{Al}^{3+}, \mathrm{Cr}^{3+}, \mathrm{Ti}^{4+}, \mathrm{Fe}^{3+}$, $\mathrm{Be}^{2+}, \mathrm{V}^{5+}$ (ионный радиус $<0.07$ нм);

2) оксиды, катионы которых не образуют твердых растворов на основе муллита и разрушают его кристаллическую структуру: $\mathrm{Ba}^{2+}, \mathrm{Co}^{3+}, \mathrm{Fe}^{2+}, \mathrm{Mg}^{2+}$, $\mathrm{Mn}^{2+}, \mathrm{Ca}^{2+}$ (ионный радиус 0.078-0.143 нм);

3) оксиды, катионы которых при любых концентрациях не разрушают структуру муллита: $\mathrm{V}_{2} \mathrm{O}_{5}$, $\mathrm{Al}_{2} \mathrm{O}_{3}, \mathrm{SiO}_{2}, \mathrm{ZrO}_{2}$.

Вводимые в структуру муллита изоморфные примеси по-разному влияют на морфологию кристаллов и их агрегатов, а также на фазовый состав 
продуктов синтеза [3]. Наиболее однородный по составу муллит получен при введении в шихту $\mathrm{C}^{3+}$, $\mathrm{V}^{3+}, \mathrm{Fe}^{3+}$ в количестве 0.2 формульных единиц. Повышение количества вводимого изоморфно замещающего компонента увеличивает толщину кристаллов, осевое число $(1 / d)$ уменьшается, увеличивается число т. н. паразитных сферолитов. Результаты анализа микродифракционных картин дают основание утверждать, что кристаллы имеют, в основном, грани (110) и (210).

Все продукты синтеза подвергались изучению на электронном микроскопе JEM-6А методами микродифракции и дифракционного контраста.

Электронно-микроскопическое исследование кристаллов, полученных при введении в систему оксидов $\mathrm{Co}^{3+}$ и $\mathrm{Ni}^{3+}$, показало, что при небольших содержаниях ионов $\mathrm{Co}^{3+}$ и $\mathrm{Ni}^{3+}$ образуется однородный по составу тонкоигольчатый муллит. С увеличением содержания $\mathrm{Co}^{3+}$ и $\mathrm{Ni}^{3+}$ кристаллы увеличиваются в размерах, а при введении этих примесей в количествах более одной формульной единицы муллит не образуется. Изоморфно замещенные кристаллы имеют нитевидную форму различной длины от 50 до 300 мкм и диаметр 5-20 мкм. Примеси представлены корундом и тридимитом ( $<10 \%$ ). Цвет конечного продукта изменялся в зависимости от вводимого оксида.

\section{ЗАКЛЮЧЕНИЕ}

Представленный обзор демонстрирует значительный интерес научного сообщества к методам синтеза муллита, его свойствам, морфологическим модификациям, существующим областям применения, в том числе в виде композитов. Представленные авторами результаты по получению и исследованию свойств изоморфно-замещенных муллитов свидетельствуют о перспективности дальнейших работ в этой области, поисков новых материалов на их основе, их всестороннего изучения для создания современных востребованных технологий.

\section{СПИСОК ЛИТЕРАТУРЫ}

1. Грошева В. М., Карпинос Д. М., Панасевич И. М. Синтетический муллит и материаль на его основе. Киев, Техника, 1971, 56 с.

2. Aksay I. A., Dabbs D. M., Sarikaya M. // J. Amer. Ceram. Soc., 1991, vol. 74, pp. 2345-2357. DOI: https://doi. org/10.1111/j.1151-2916.1991.tb06768.x

3. Яроцкая Е. Г., Полянский Е. В, Яроцкий В. Г., Голенко В. П. В сб.: Синтез минералов. Александров: ВНИИСИМС, 2000, т. 2, с. 142-178.

4. Scneider H., Komarneri S. Mullite. Weinheim: WILEY-VCH, 2005, 487 p.
Таблица 1. Оптические характеристики изоморфно замещенных муллитов

[Table 1. Optical characteristics of isomorphically substituted mullite]

\begin{tabular}{|c|c|c|c|}
\hline \multirow{2}{*}{$\begin{array}{c}\text { Формула } \\
\text { [Formula] }\end{array}$} & \multicolumn{2}{|c|}{$\begin{array}{c}\text { Показатели } \\
\text { преломления } \\
\text { [Refractive index] }\end{array}$} & \multirow{2}{*}{$\begin{array}{c}\text { Цвет } \\
\text { [Color] }\end{array}$} \\
\cline { 2 - 3 } & $n_{p}$ & $n_{g}$ & \\
\hline $\mathrm{Al}_{5.6} \mathrm{~V}_{0.4} \mathrm{Si}_{2} \mathrm{O}_{13}$ & 1.656 & 1.670 & $\begin{array}{c}\text { Кремовый } \\
\text { [Cream] }\end{array}$ \\
\hline $\mathrm{Al}_{5.8} \mathrm{Cr}_{0.2} \mathrm{Si}_{2} \mathrm{O}_{13}$ & 1.649 & 1.666 & $\begin{array}{c}\text { Розовый } \\
\text { [Pink] }\end{array}$ \\
\hline $\mathrm{Al}_{5.8} \mathrm{Mn}_{0.2} \mathrm{Si}_{2} \mathrm{O}_{13}$ & 1.646 & 1.666 & $\begin{array}{c}\text { Коричне- } \\
\text { вый } \\
\text { [Вrown] }\end{array}$ \\
\hline $\mathrm{Al}_{5.8} \mathrm{Fe}_{0.2} \mathrm{Si}_{2} \mathrm{O}_{13}$ & 1.648 & 1.666 & $\begin{array}{c}\text { Серый } \\
\text { [Gray] }\end{array}$ \\
\hline $\mathrm{Al}_{5.2} \mathrm{Co}_{0.8} \mathrm{Si}_{2} \mathrm{O}_{13}$ & 1.652 & 1.668 & $\begin{array}{c}\text { Синий } \\
\text { [Вlue] }\end{array}$ \\
\hline $\mathrm{Al}_{5.4} \mathrm{Ni}_{0.6} \mathrm{Si}_{2} \mathrm{O}_{13}$ & 1.650 & 1.667 & $\begin{array}{c}\text { Аквамари- } \\
\text { новый } \\
\text { [Аquата- } \\
\text { rine] }\end{array}$ \\
\hline
\end{tabular}

5. Scneider H., Fischer R. X., Screuer J. // J. Amer. Ceram. Soc., 2015, vol. 98, pp. 2948-2967. DOI: https://doi. org/10.1111/jace. 13817

6. Матвеева Ф. А. Синтез муллита из каолинита и фтористого алюминия. В сб.: Физико-химическое исследование алюмосиликатных и изирконий-содержащзих систем и минералов. Новосибирск, 1972, с. 48-57.

7. Durovich S., Feidi P. // Silicat., 1976, vol. 20, pp. 97-112.

8. Cameron W. E. // Amer. Mineralogist, 1977, vol. 62, pp. 747-755.

9. Aksay I. A., Dabbs D. M., Sarikaya M. J. // J. Am. Ceram. Soc., 1991, vol. 74, № 10, pp. 2343-2357. DOI: https://doi.org/10.1111/j.1151-2916.1991.tb06768.x

10. Padlewski S., Heine V., Price G. D. // J. Phys.: Condens. Matter, 1993, vol. 5, pp. 3417-3430. DOI: https:// doi.org/10.1088/0953-8984/5/21/004

11. Андреев В. А. Фтораммонийная технология получения муллита из топазового концентрата. Автореферат дисс. ... к. т. н., Северская государственная технологическая академия (СГТА), Томский политехнический университет (ТПУ), Томск, 2007, 22 с.

12. Mailliart O., Chaumat V., Hodaj F. // J. Mater.Sci., vol. 45, 2010, pp. 2126-2132. DOI: https://doi.org/10.1007/ s10853-009-3950-5

13. Grohol D., Han C., Pyzik A., et al. // J. Amer. Ceram. Soc., 2010, vol. 93, pp. 3600-3603. DOI: https://doi. org/10.1111/j.1551-2916.2010.04129.x

14. Hoo C. M., Men D., Taherabadi L., Mecartneyw M. L. // J. Amer. Ceram. Soc., 2011, vol. 94, pp. 2171-2180. DOI: https://doi.org/10.1111/j.1551-2916.2010.04348.x 


\section{Е. Г. ЯРОЦКАЯ, П. П. ФЕДОРОВ}

15. Bodhak S., Bose S. and Bandyopadhyayw A. // J. Mater. Sci., 2011, vol. 94, pp. 32-41. DOI: https://doi. org/10.1111/j.1551-2916.2010.04062.x

16. Popa C., Okayasu Y., Katsumata K., et al. // J. Mater. Sci., 2011, vol. 48, № 2, pp. 941-947. DOI: https://doi. org/10.1007/s10853-012-6819-y

17. Lambotte G., Chartrand P. // J. Amer. Ceram. Soc., 2011, vol. 94, pp. 4000-4008. DOI: https://doi.org/10.1111/ j.1551-2916.2011.04656.x

18. Kalita P., Scneider H., Lipinska K., et. al. // J. Amer. Ceram. Soc., 2013, vol. 96, № 5, pp. 1635-1642. https://doi. org/10.1111/jace. 12191

19. Ingemarsson L., Hellstrom K., Canovic S., et. al. // J. Mater. Sci., 2013, vol. 48, pp. 1511-1523. DOI: https://doi. org/10.1007/s10853-012-6906-0

20. Chen M., Zhao B. // J. Amer. Ceram. Soc., 2013, vol. 96, pp. 3631-3636. DOI: https://doi.org/10.1111/ jace. 12573

21. Беляков А. В., Попова Н. А., Гринберг Е. Е., Стрельникова И. Е., Амелина А. Е., Левин Ю. И. // Перспективные материаль, 2014, № 12, с. 66-73.

22. Yu P.-C., Tsan Y.-W., Yen F.-S., et. al. // J. Amer. Ceram. Soc., 2014, vol. 97, pp. 2431-2438. DOI: https://doi. org/10.1111/jace.12989

23. Malki M., Hoo C. M., Mecartney M. L. Schneider H. // J. Amer. Ceram. Soc., 2014, vol. 97, pp. 19231930. DOI: https://doi.org/10.1111/jace.12867

24. Kalita P., Cornelius A., Lipinska K., et. al. // J. Amer. Ceram. Soc., 2014, vol. 97, pp. 2980-2989. DOI: https://doi. org/10.1111/jace. 13027

25. Mandic V., Tkal E., Kurajica S. // J. Amer. Ceram. Soc., 2014, vol. 97, pp. 2264-2271. DOI: https://doi. org/10.1111/jace. 12887

26. Вакалова Т. В., Хабас Т. А., Погребенков В. М., Бирюкова А. А. // Международный журнал прикладных и фундаментальныхх исследований, 2015, № 5, с. 379384.

27. Стрельникова С. С., Андрианов Н. Т., Анохин А. С. // Труды Кольского научного иентра РАН, 2015, c. $479-482$.

28. Richards B., Begley M. R., Wadley H. N.G. // J. Amer. Ceram. Soc., 2015, vol. 98, pp. 4066-4075. DOI: https://doi.org/10.1111/jace.13792

29. Chen Z., Gu Y., Kornev K., et. al. // J. Amer. Ceram. Soc., 2016, vol. 99, pp. 1504-1511. DOI: https://doi. org/10.1111/jace. 14148
30. Zeng D.-J., Zhang Y.-M, Yang J.-F., Wang B., Matsushita J. // J. Amer. Ceram. Soc., 2016, vol. 99, pp. 2226-2228. DOI: https://doi.org/10.1111/jace.14309

31. Kocjan A., Ce M., Vengust D., et. al. // J. Amer. Ceram. Soc., 2016, vol. 99, pp. 3090-3096. DOI: https://doi. org/10.1111/jace. 14302

32. Пимков Ю. В. Синтез муллита из активированнblх прекурсоров и композиционные материаль на его основе. Автореферат дисс. ... к. т. н., 2016, Иваново, $16 \mathrm{c.}$

33. Kitaoka S., Matsudaira1 T., Yokoe D., et. al. // J. Amer. Ceram. Soc., 2017, vol. 100, pp. 3217-3226. DOI: https://doi.org/10.1111/jace.14834

34. Igami Y., Ohi S., Miyake A. // J. Amer. Ceram. Soc., 2017, vol. 100, pp. 4928-4937. DOI: https://doi.org/10.1111/ jace. 15020

35. Murshed M. M., Sehovi M., Fischer M., et. al. // J. Amer. Ceram. Soc., 2017, vol. 100, pp. 5259-5273. DOI: https://doi.org/10.1111/jace.15028

36. Romero A. R., Elsayed H., Bernardo E. // J. Amer. Ceram. Soc., 2018, vol. 101, pp. 1036-1041. DOI: https:// doi.org/10.1111/jace.15327

37. Krenzel T., Schreuer J., Laubner D., et. al. // J. Amer. Ceram. Soc., 2018, DOI: 10.1111/jace.15925. DOI: https:// doi.org/10.1111/jace.15925

38. Song X., Ma Y., Wang J., et. al. // J. Mater. Sci., 2018, pp. 14871-14883. DOI: https://doi.org/10.1007/ s10853-018-2667-8

39. Almeida R., Bergmuller E., Luhrs H., et. al. // J. Amer. Ceram. Soc., 2018, vol. 100, pp. 4101-4109. DOI: https://doi.org/10.1111/jace. 14922

40. Dong X., Liu J., Li X., et. al. // J. Amer. Ceram. Soc., 2018, vol. 100, pp. 3425-3433. DOI: https://doi.org/10.1111/ jace. 14917

41. Zang W., Jia T., Dong X., et. al. J. Amer. Ceram. Soc., 2018, vol. 101, pp. 3138-3147. DOI: https://doi. org/10.1111/jace. 15441

42. Пенкаля Т. Очерки кристаллохимии. Л.: Химия, 1974, $496 \mathrm{c}$.

43. Федоров П. П. // Журн. физич. химии, 1999, т. 73, c. $1551-1556$.

44. Федоров П. П. // Журн. неорган. химии, 2012, т. 57, с. 1033-1043. DOI: https://doi.org/10.1134/ S003602361207011X

45. Яроцкая Е. Г., Федоров П.П. Конденсированные среды и межфазные границы, 2018, т. 20, № 3, с. 348 353. DOI: https://doi.org/10.17308/kcmf.2018.20/571 


\title{
MULLITE AND ITS ISOMORPHIC SUBSTITUTION OVERVIEW
}

\author{
(C) 2018 E. G. Yarotskaya, P. P. Fedorov
}

\begin{abstract}
Prokhorov General Physics Institute of the Russian Academy of Sciences, 38, Vavilova str., 119991 Moscow, Russia e-mail: yar461@yandex.ru
\end{abstract}

Received 18.09.2018

\begin{abstract}
The phase diagram of $\mathrm{SiO}_{2}-\mathrm{Al}_{2} \mathrm{O}_{3}$ is considered. The paper presents an overview of the methods of synthesising mullite, including the calcining of natural aluminosilicates, the Czochralski process (synthesising mullite from melt), the Verneuil process (synthesising mullite from gel), and the solid state method (synthesising mullite from the mixture of stoichiometric composition). Previous studies have determined that the parameters of the orthorhombic lattice and the habitus of mullite crystals depend directly on the ratio of aluminum and silicon in the initial batch, the content of impurities, the method of heat treatment, and the form of introduction of the initial components into the batch. The size of the mullite crystals is affected by the presence of aluminum fluoride in the batch, which at a certain ratios allows to obtain the final product in the form of whiskers. The effect of mineralizers on the yield of mullite was considered: alkali metal fluorides reduce the yield, while sulfates and chlorides increase it and also influence the viscosity and structure of the melt. In order to determine the effect, we studied the influence of various additives on the process, structure, and properties of the synthesis. Structural features of the mullite crystal lattice affecting isomorphic substitutions were determined. The paper also considers the possibility of obtaining isomorphically substituted mullite varieties, and presents the optical characteristics of isomorphically substituted mullite containing $d$-elements.
\end{abstract}

Keywords: mullite, synthesis, structure, habit, whiskers, isomorphous substitutions.

DOI: https://doi.org/10.17308/kcmf.2018.20/626

\section{REFERENCES}

1. Grosheva V. M., Karpinos D. M., Panasevich I. M. Synthetic Mullite and Materials Based on It. Kiev, Tekhnika Publ, 1971, 56 p. (in Russ.)

2. Aksay I. A., Dabbs D. M., Sarikaya M. J. Amer. Ceram. Soc., 1991, vol. 74, pp. 2345-2357. DOI: https://doi. org/10.1111/j.1151-2916.1991.tb06768.x

3. Yarotskaya E. G., Polyanskiy E. V., Yarotskiy V. G., Golenko V. P. In: Synthesis of Minerals. Alexandrov: VNIISIMS Publ., 2000, vol. 2, pp. 142-178. (in Russ.)

4. Scneider H., Komarneri S. Mullite. Weinheim: WILEY-VCH, 2005, 487 p.

5. Scneider H., Fischer R.X., Screuer J. J. Amer. Ceram. Soc., 2015, vol. 98, pp. 2948-2967. DOI: https://doi. org $/ 10.1111 /$ jace. 13817

6. Matveeva F. A. In: Physico-Chemical Study of Aluminosilicate and Zirconium-Containing Systems and Minerals. Novosibirsk Publ., 1972, pp. 48-57. (in Russ.)

7. Durovich S., Feidi P. Silicat., 1976, vol. 20, pp. 97112.

8. Cameron W. E. Amer. Mineralogist, 1977, vol. 62, pp. 747-755.

9. Aksay I. A., Dabbs D. M., Sarikaya M. J. Amer. Ceram. Soc., 1991, vol. 74, no. 10, pp. 2343-2357. DOI: https://doi.org/10.1111/j.1151-2916.1991.tb06768.x
10. Padlewski S., Heine V., Price G. D. J. Phys.: Condens. Matter, 1993, vol. 5, pp. 3417-3430. DOI: https:// doi.org/10.1088/0953-8984/5/21/004

11. Andreev V. A. Fluoroammonium Technology of Mullite Production from Topaz Concentrate. Thesis Ph.D., Tomsk, 2007, 22 p. (in Russ.)

12. Mailliart O., Chaumat V., Hodaj F. J. Mater.Sci., vol. 45, 2010, pp. 2126-2132. DOI: https://doi.org/10.1007/ s10853-009-3950-5

13. Grohol D., Han C., Pyzik A., et al. J. Amer. Ceram. Soc., 2010, vol. 93, pp. 3600-3603. DOI: https://doi. org/10.1111/j.1551-2916.2010.04129.x

14. Hoo C. M., Men D., Taherabadi L. and Mecartneyw M. L. J. Amer. Ceram. Soc., 2011, vol. 94, pp. 2171-2180. DOI: https://doi.org/10.1111/j.1551-2916.2010.04348.x

15. Bodhak S., Bose S. and Bandyopadhyayw A. J. Mater. Sci., 2011, vol. 94, pp. 32-41. DOI: https://doi. org/10.1111/j.1551-2916.2010.04062.x

16. Popa C., Okayasu Y., Katsumata K., et al. J. Mater. Sci., 2011, vol. 48, no. 2, pp. 941-947. DOI: https://doi. org/10.1007/s10853-012-6819-y

17. Lambotte G., Chartrand P. J. Amer. Ceram. Soc., 2011, vol. 94, pp. 4000-4008. DOI: https://doi.org/10.1111/ j.1551-2916.2011.04656.x 


\section{Е. Г. ЯРОЦКАЯ, П. П. ФЕДОРОВ}

18. Kalita P., Scneider H., Lipinska K., et. al. J. Amer. Ceram. Soc., 2013, vol. 96, no. 5, pp. 1635-1642. DOI: https://doi.org/10.1111/jace.12191

19. Ingemarsson L., Hellstrom K., Canovic S., et. al. $J$. Mater. Sci., 2013, vol. 48, pp. 1511-1523. DOI: https://doi. org/10.1007/s10853-012-6906-0

20. Chen M., Zhao B. J. Amer. Ceram. Soc., 2013, vol. 96, pp. 3631-3636. DOI: https://doi.org/10.1111/ jace. 12573

21. Belyakov A. V., Popova N. A., Grinberg E.E., Strely̆nikova I. E., Amelina A. E., Levin Yu. I. Perspektivnye Materialy, 2014, no. 12, pp. 66-73. (in Russ.)

22. Yu P.-C., Tsan Y.-W., Yen F.-S., et. al. J. Amer. Ceram. Soc., 2014, vol. 97, pp. 2431-2438. DOI: https://doi. org/10.1111/jace. 12989

23. Malki M., Hoo C. M., Mecartney M. L., Schneider H. J. Amer. Ceram. Soc., 2014, vol. 97, pp. 1923-1930. DOI: https://doi.org/10.1111/jace.12867

24. Kalita P., Cornelius A., Lipinska K., et. al. J. Amer. Ceram. Soc., 2014, vol. 97, pp. 2980-2989. DOI: https://doi. org/10.1111/jace. 13027

25. Mandic V., Tkal E., Kurajica S. J. Amer. Ceram. Soc., 2014, vol. 97, pp. 2264-2271. DOI: https://doi. org/10.1111/jace.12887

26. Vakalova T. V., Khabas T. A., Pogrebenkov V. M., Birukova A. A. Mezhdunarodnyi Journal prikladnyh I fundamental'nyh issledovanii [International Journal of Applied and Basic Research], 2015, no. 5, pp. 379-384. (in Russ.)

27. Strelnikova S. S., Andrianov N. T., Anokhin A. S. Trudy Kol'skogo nauchnogo centra RAN [Works of the Kola Scientific Center of the Russian Academy of Sciences], 2015, pp. 479-482. (in Russ.)

28. Richards B., Begley M. R., Wadley H. N. G. J. Amer. Ceram. Soc., 2015, vol. 98, pp. 4066-4075. DOI: https://doi. org/10.1111/jace. 13792

29. Chen Z., Gu Y., Kornev K., et. al. J. Amer. Ceram. Soc., 2016, vol. 99, pp. 1504-1511. DOI: https://doi. org/10.1111/jace. 14148

30. Zeng D.-J., Zhang Y.-M, Yang J.-F., Wang B., Matsushita J. J. Amer. Ceram. Soc., 2016, vol. 99, pp. 22262228. DOI: https://doi.org/10.1111/jace.14309
31. Kocjan A., Ce M., Vengust D., et. al. J. Amer. Ceram. Soc., 2016, vol. 99, pp. 3090-3096. DOI: https://doi. org/10.1111/jace. 14302

32. Pimkov Yu. V. Synthesis of Mullite From Activated Precursors and Composite Materials Based on It. Thesis Ph.D., 2016, Ivanovo Publ., 16 p. (in Russi.)

33. Kitaoka S., Matsudaira1 T., Yokoe D., et. al. J. Amer. Ceram. Soc., 2017, vol. 100, pp. 3217-3226. DOI: https:// doi.org/10.1111/jace.14834

34. Igami Y., Ohi S., Miyake A. J. Amer. Ceram. Soc., 2017, vol. 100, pp. 4928-4937. DOI: https://doi.org/10.1111/ jace. 15020

35. Murshed M. M., Sehovi M., Fischer M., et. al. $J$. Amer. Ceram. Soc., 2017, vol. 100, pp. 5259-5273. DOI: https://doi.org/10.1111/jace. 15028

36. Romero A. R., Elsayed H., Bernardo E. J. Amer. Ceram. Soc., 2018, vol. 101, pp. 1036-1041. DOI: https:// doi.org/10.1111/jace. 15327

37. Krenzel T., Schreuer J., Laubner D., et. al. J. Amer. Ceram. Soc., 2018. DOI: https://doi.org/10.1111/ jace. 15925

38. Song X., Ma Y., Wang J., et. al. J. Mater. Sci., 2018, pp. 14871-14883. DOI: https://doi.org/10.1007/s10853-0182667-8

39. Almeida R., Bergmuller E., Luhrs H. et. al. J. Amer. Ceram. Soc., 2018, vol. 100, pp. 4101-4109. DOI: https:// doi.org/10.1111/jace.14922

40. Dong X., Liu J., Li X., et. al. J. Amer. Ceram. Soc., 2018, vol. 100, pp. 3425-3433. DOI: https://doi.org/10.1111/ jace. 14917

41. Zang W., Jia T., Dong X., et. al. J. Amer. Ceram. Soc., 2018, vol. 101, pp. 3138-3147. DOI: https://doi. org/10.1111/jace. 15441

42. Penkalia T. Essays on Crystal Chemistry. Leningrad, Khimiya Publ., 1974, 496 c. (in Russ.)

43. Fedorov P. P. Russ. J. Phys. Chem., 1999, vol. 73, no. 9, pp. 1387-1392. (in Russ.)

44. Fedorov P. P. Russ. J. Inorg. Chem., 2012. vol. 57, no. 7, pp. 959-969. DOI: https://doi.org/10.1134/ S003602361207011X

45. Yarotskaya E. G., Fedorov P. P. Condensed Matter and Interphases, 2018, vol. 20, no. 3 pp. 348-353. DOI: https://doi.org/10.17308/kcmf.2018.20/571 (in Russ.)
Яроцкая Евгения Григорьевна - к. х. н., и. о. н. с., Институт общей физики им. А. М. Прохорова РАН (ИОФ РАН), Москва, Россия; тел.: +7 (499) 1357744, e-mail: yar461@yandex.ru

Федоров Павел Павлович - д. х. н., профессор, заведующий лабораторией, Институт общей физики им. А. М. Прохорова РАН (ИОФ РАН), Москва, Россия; тел.: +7 (499) 5038292, e-mail: ppfedorov@ yandex.ru
Evgeniya G. Yarotskaya - Cand. Sci. (Chem.), Prokhorov General Physics Institute, RAS (GPI RAS), Moscow, Russia; tel.: +7 (499) 1357744, e-mail: yar461@yandex.ru

Pavel P. Fedorov-Dr. Sci. (Chem.), Full Professor, Laboratory Head, Prokhorov General Physics Institute RAS (GPI RAS), Moscow, Russia; tel.: +7 (499) 5038292, e-mail: ppfedorov@yandex.ru 